have revealed that certain species hitherto regarded as uncommon or even extremely rare are, in reality, not only prevalent but even possibly widespread. Nothing is as yet known of their economic importance.

Researches are in progress, or are projected, on many aspects of tsetse entomology. These include studies on the longevity, dispersal, breeding habits, feeding habits, infectivity, etc., of different species at various seasons. Laboratory experiments designed to supplement and serve as a check on observations made in the field are now being commenced, as well as further studies on the systematics and physiology of tsetse and such other biting flies as may be incriminated as vectors. A prerequisite to these investigations, and especially to the future work of the Protozoology Section, is the availability of large numbers of clean flies, and high priority has therefore been given to the laboratory rearing of tsetseflies on a large scale. The Entomology Section is also responsible for investigating the value of arboricides, insecticides and repellants in the control of trypanosomiasis.

Remarkably little work has hitherto been done on the epidemiology of either human or animal trypanosomiasis, and the study of this subject is the special responsibility of the Epidemiology Section. It has been possible to trace the origin of the severe and widespread epidemics of sleeping sickness which have occurred in Northern Nigeria during the present century to two endemic foci-one in the vicinity of the Niger-Benue confluence and the other in the Lake Chad basin. It has been shown that these epidemics were precipitated primarily by the dispersal of infected individuals consequent upon the settled conditions resulting from British occupation of the country, which facilitated the opening up of communications, the extension of agriculture and the introduction of such new industries as tin mining. There is no evidence that alteration in the prevalence or distribution of insect vectors played any appreciable part in the causation of these epidemics. Two isolated epidemics have recently been subjected to detailed investigation. Future work lies mainly in the elucidation of the intricate complexity of factors which favour or limit the spread of trypanosomiasis under natural conditions and will necessitate the careful study of selected communities, their environment and activities, in relation to the insect vector and the reservoir of infection.

In the veterinary sphere it is imperative to ascertain the true extent of the losses from trypanosomiasis which occur among domestic stock; to ascertain how, when and where such infections are acquired; to demarcate the danger zones; to study movements of stock in relation to tsetse; and to consider ways and means of minimizing the losses which occur. This, in turn, involves a careful study of grazing areas, the migrations of nomadic cattle, the movements of trade cattle, and the conditions under which settled stock is maintained. Much more accurate knowledge is required of factors which may influence the severity of trypanosome infections in stock, such as heredity, nutritional deficiencies, intercurrent infections, immunizing procedures against other diseases, exposure to adverse environmental conditions, etc.

The protozoology of both human and animal trypanosomiasis requires much fuller investigation. Apart from further systematic studies on the trypanosomes, there is an urgent need for improved diagnostic procedures, especially of cryptic infections; for studies on the life-history of the trypanosomes in both vertebrate and invertebrate hosts ; for immunological researches; and for ascertaining the factors governing the development, infectivity, transmissibility and pathogenicity of various species and strains of trypanosomes. Facilities are available for using cyclically transmitted strains in experiments of this kind. The chemotherapy and chemoprophylaxis of both human and animal trypanosomiasis are subjects which are currently receiving much attention and which are likely to continue to require constant research work. Experiments carried out during the past yoar have done much to indicate the circum. stances in which 'Antrycide' might be used in the prevention of cattle trypanosomiasis.

It is a constant concern of the Institute to devise and test such new measures for the control of trypano. somiasis as may be suggested by the acquisition of fresh knowledge in any of its many and varied spheres of research.

\section{CIRCULATION OF WATER IN THE OCEANS}

A T a meeting at the Royal Astronomical Society on January 26, a Geophysical Discussion was held with the object of clarifying and co-ordinating our knowledge of the motion of large masses of water in the oceans. After opening contributions by an oceanographer and a meteorologist, a lively debate ensued in which oceanographers, meteorologists, astrophysicists, sailors and a hydraulic engineer all took part. Many will hope that in future greater attention will be given in Great Britain to this tantalizing and by no means 'useless' branch of science.

Dr. G. E. R. Deacon set the tone of the meeting with a critical review of the development of our knowledge of oceanic circulations. He referred to Croll's statement that "few subjects have excited more interest and attention than the cause of ocean circulation and yet few are in a more imperfect and unsatisfactory condition" ; and he agreed with him that the principal reason why progress is still slow is that "the question is one which properly belongs to the domain of physics and mechanics", whereas few physicists of note have as yet given the subject special attention. Dr. Deacon's account contained many instances of progress being held up by lack of the appropriate specialized knowledge.

It was known before the eighteenth century that the temperature of the water near the bottom of the sea is low; but it was not until 1810 that Humboldt suggested that this cold water has come from the polar regions, sinking to the bottom because of its greater density. Later, in 1856, Maury extended this idea and asserted that all water movements, surface as well as deep, are caused by density differences.

Some time afterwards, these views were opposed by Croll (a geologist), who believed that the density differences were too small to account for the currents. He supported his assertions by referring to model experiments, and was led into a protracted argument with Carpenter (a biologist); but neither was ever able to convince the other, perhaps mainly because neither was able to get a proper grasp of the problem. (Croll's inferences from experiments are, in fact, invalid, because of the omission of a scale factor.) 
Up to this time there had been few facts on which to base theories, and the motion of the deep water was merely inferred. Not until after the Challenger Expedition of 1873-76 had made deep soundings of temperature and salinity over wide areas was it possible to get a clear picture of the actual distribution from which one might attempt to estimate the currents. Since then, the areas have been extended and details filled in by other expeditions, such as that of the Meteor during 1925-27. We now know that many of the permanent currents in the ocean (especially those prominent at the surface) are maintained by the stress of the wind, but the exact relationship has yet to be discovered. On the other hand, there is evidence that heating and cooling and evaporation control the motion of large masses of water in other circulations. Dr. Deacon instanced the (vertical) eirculation in the Mediterranean, where light surface water flows in through the Straits of Gibraltar above the heavy saline deep water which flows out. (The Mediterranean is a region where evaporation exceeds precipitation and run-off, so that were it not for this circulation the water would become steadily more saline and dense.) A similar deep circulation occurs in the Red Sea throughout the year-in spite of the monsoonal reversal in the wind direction.

On a larger scale, there is evidence from Wüst's sections showing salinity distribution (in a vertical north-south plane) in the Atlantic, pointing to a grand deep circulation. Cold heavy water appears to sink in the Arctic and flows as a deep current across the equator, rising again in the Antarctic above still denser water from the Antarctic shelf, and reaching nearly to the surface below rather less dense Antarctic oceanic water. The latter seems to move northwards and then dip down at the Antarctic Convergence below the lighter sub-antarctic water, flowing on at an intermediate depth and even crossing the equator. Density differences would appear to be of paramount importance in all these circulations, but it cannot be said that they are yet satisfactorily explained.

In order to be able to assess the relative importance of wind-stress and density gradient in determining the motion of water, we need more accurate knowledge not only of the stress exerted by the wind but also of the internal (Reynolds's) stresses in the ocean itself. Dr. Deacon hoped that the small band of oceanographers working on this problem would be assisted by meteorologists, who are faced by very similar problems and who in turn may well be helped as a result of a more detailed study of the oceans.

Dr. E. T. Eady agreed with this last remark and pointed out that the equations governing the motion of the oceans are similar to those governing atmospheric motion. Differences between meteorology and oceanography result from differences in the boundary conditions (for example, the atmosphere has no lateral boundaries), from differences in the location of radiation input and output (at different levels in the atmosphere but nearly the same level in the oceans) which affect the possibility of motion being generated by a thermal 'engine', and by the opposite roles taken by friction between air and water (in the case of the atmosphere a destroyer, in the case of the oceans a generator, of motion).

Over most of the oceans, except in a surface layer of something like $100 \mathrm{~m}$. where friction is important, the currents are, as in the atmosphere, nearly geostrophic, and there is a simple relation between average current and pressure gradient. It follows that there is a simple relation between density distribution, which is accurately known, and the variation of current with depth. Hence to compute the currents in the ocean we need only a direct measurement at one level, or alternatively the pressure distribution at one level. Unfortunately, it is very difficult to determine either of these with sufficient accuracy. For want of anything better, the conservatism of many properties, such as salinity, is sometimes made use of in attempting to trace the history of water masses; but the results are always qualitative and may even be in error if the results of eddy-diffusion are not, or cannot be, properly taken into account. However, in certain cases it is possible to use the equations of motion to give numerical estimates of circulation as a whole.

Dr. Eady first considered circulations in a horizontal plane such as that in the Atlantic, a prominent feature of which is the Gulf Stream. One of the derived equations relates the vertical component of absolute vorticity (which may be thought of as twice the 'spin' of the ocean currents plus twice the vertical component of the earth's 'spin') of a column of water to the curl (or twice the 'twist') of the external stresses plus the vorticity diffused by internal stresses. Over most of the oceans the 'spin' associated with the currents is very small compared with the component of the earth's 'spin', measured by the Coriolis factor, and we find that if the external stresses are anticyclonic (clockwise in the northern hemisphere) the water must in the absence of internal stresses be moving towards the equator. If we suppose that bottom stresses are small, the main external stress is that due to the wind, and the state of affairs in latitude $30^{\circ} \mathrm{N}$. is as has been described. But the Atlantic Ocean is nearly closed and almost as much water must be moving away from the equator as is moving to it. Hence in some parts at least of the ocean both bottom stresses and internal stresses must play an important part. Munk has discovered the appropriate solution of this problem. Over most of the ocean there is a drift towards the equator, but on the western side friction with the bottom overpowers the effect of the wind, and the water moves poleward. The current is narrow because the 'mixing-length' of large-scale turbulence in the ocean is small compared with that in the atmosphere and this current is identified with the Gulf Stream. In this way Munk accounts for most of the major surface currents in the oceans (except for the Antarctic current), and his solutions are very life-like. Given the wind-stress, the theory enables one to compute the total transport by such currents. The stresses assumed by Munk are probably exaggerated, but even so the transport computed is less than that usually assumed by oceanographers in the case of the Gulf Stream and Kuroshio. Further examination indicates other discrepancies, and it is not yet clear to what extent these are due to errors in wind-stress and to what extent they are due to errors in guessing the level of no motion.

Dr. Eady next considered the grand vertical circulation in the Atlantic. In this case the continuity equation may be used for determining the mean level of no motion. Then the strength of the circulation may be estimated from the density distribution. Computations by Dr. Eady at latitudes between $35^{\circ} \mathrm{S}$. and $60^{\circ} \mathrm{N}$. for every $5^{\circ}$, except the equator and $15^{\circ}$ and $20^{\circ} \mathrm{N}$. (for which data were not available), yielded in every case a circulation with an upper flow towards the north and a deep current to 
the south, agreeing with Dr. Deacon's inferences from Wüst sections. The mean circulation came to about $10 \times 10^{6} \mathrm{~m}^{3} / \mathrm{sec}$., agreeing reasonably well with Sverdrup's estimate of $6 \times 10^{6} \mathrm{~m} .{ }^{3} / \mathrm{sec}$. by other methods for the circulation across the equator. The heat transported by such a circulation must have an important climatological effect, as previously indicated by F. Model. There is some doubt regarding the exact value of the flow, because modifications are possible when the varying depth of the ocean is taken into account. Also currents balancing the wind-stress have been ignored; but these may be expected to be nearly symmetrical about the equator, whereas those computed are asymmetrical. Regarding the cause of this circulation, Dr. Eady hazarded the guess that the difference in ocean geography between the hemispheres is responsible. The wind-stress in the 'Roaring Forties' must generate a vertical circulation which in the absence of land barriers would cause descent near $30^{\circ} \mathrm{S}$. But the Atlantic, unlike the Antaretic, is bounded laterally, and it seems possible that the water follows the path of least resistance, flowing up to high latitudes where its high density enables it to be easily forced down. (The existence of a land boundary is necessary to enable the water to adjust its angular momentum, through external pressure, during its change of latitude.)

Dr. Eady also referred briefly to the fact that the Antarctic Convergence remains statistically stationary, although there should be a wind-driven transport of the upper layers to the north. The mass and velocity distribution at the convergence is exactly similar to that at a 'front' in the atmosphere, and we should expect similar developments. At meteorological 'fronts', unstable waves grow into eyclones and anticyclones, giving rise to a kind of large-scale turbulence. The effect of this turbulence is that, at the top of the atmosphere, the warm air flows around tongues of cold air which eventually descend and are replaced by warm air flowing in sideways. In this way the warm air as a whole moves forward. (This is the counterpart of the more familiar events near the ground, where the cold air advances.) Translating into oceanographic terms, we find the behaviour near the Antarctic Convergence intelligible. The turbulent progress of the warm sub-arctic water just balances the wind-driven current. On the other hand, there appears to be good evidence for the existence of the supposed turbulent eddies, and oceanographic data suggest that they are of the size (much smaller than in the atmosphere) to be expected theoretically.

In the ensuing discussion, Prof. P. A. Sheppard described some observations made to determine the value of the coefficient of drag of the air over the sea. The method involved a calculation from accurate pilot-balloon data of the flow of air across the isobars, and in the hands of R. C. Sutcliffe had previously suggested a value much lower than that over land. A preliminary analysis of the results with new data was given by Mr. H. Charnock, who indicated that these suggested a very low value for the coefficient of drag. He also directed attention to the very wide scatter between different estimates of this fundamental quantity. Mr. J. R. D. Francis described some experiments he had made with flow of air over artificially produced waves in a wind-tunnel. According to his results, the coefficient of drag increases with wind speed, and he claimed that this conclusion fitted the general trend of results by other methods.
In view of the general desire to obtain advice from experts in allied fields of study, Prof. W. H. McCrae was pressed to give the views of an astrophysicist. He regretted that he found too great a difference between stellar atmospheres and ocean currents, the boundary conditions being quite different. However, we may hope that nevertheless astrophysicists and dynamical oceanographers and meteorologists will one day find that, in spite of differences, there is some similarity between their problems, and that as a result they may be able to offer each other some assistance.

\section{OBITUARIES}

\section{Dr. Edward Greenly}

The death of Edward Greenly on March 4 has removed a highly respected 'elder' of the geological community. Born at Bristol on December 3, 1861, Greenly lived to be oldest Fellow of the Geological Society and sole survivor of the little band connected with the geological conquest of the North-West Highlands. In other directions his memories included the Franco-Prussian War; while his father, as a medical student, had 'snatched' a body in pursuit of knowledge.

Greenly first felt the call of geology one glorious August morning in 1884 on Cader Idris. Though by this time an articled clerk in a lawyer's office, he was allowed to make a fresh start at the University of London. Here he supplemented his course by wellchosen excursions, one of which led to a chance encounter with Green, at that time professor of geology at Leeds. Six days together in the field prompted the latter, on his own initiative, to recom. mend his young friend to Geikie, should there be a vacancy on the Geological Survey. So Geikie in 1889 summoned Greenly for an interview, and offered him a post. During the conversation the recruit confided his desire to meet Peach and Horne and see their famous thrusts. To which Geikie replied with a smile: "That's just where you are going". Shortly afterwards he was with Peach, Horne and Clough"Each one of them resembled the children of a king .. to a young surveyor, picture what it was to be thrown into such society".

Greenly remained on the Geological Survey until 1895. During this period he was the first to point out that Moine schists are sometimes recognizable grits-Lapworth, Peach and Horne had mistaken them for a product of crushing. He also threw light on granitic impregnation. More important, perhaps, he began to emulate Clough's minutely accurate six. inch mapping. He ascribes this last to the influence of his wife, Annie, whom he married in 1891. Put briefly, he decided to regard a truthful, beautiful map as an end in itself, whether he could understand its significance or not; and to distinguish in it very clearly between observation and inference.

In 1895 Greenly resigned from the official Survey, for the sake of his wife, and started upon an unofficial survey of Anglesey-something as near the Scottish Highlands in character as he could find south of the border. Though much good work, both official and unofficial, had been accomplished there in the past, almost all the mapping had been on the one-inch scale, and it was clear that a great opportunity lay before him. So Greenly set to work on a six-inch survey in 1895 and finished in 1910. It is doubtful 